NBER WORKING PAPER SERIES

\title{
AUCTIONS VS. NEGOTIATIONS
}

\author{
Jeremy Bulow
}

Paul Klemperer

Working Paper No. 4608

\section{NATIONAL BUREAU OF ECONOMIC RESEARCH 1050 Massachusetts Avenue Cambridge, MA 02138 \\ January, 1994}

Thanks to Margaret Meyer, John Roberts, and Lawrence Summers, as well as other colleagues at Stanford Business School and Oxford University for valuable comments. This paper of part of NBER's research program in Corporate Finance. Any opinions expressed are those of the authors and not those of the National Bureau of Economic Research. 


\title{
AUCTIONS VS. NEGOTIATIONS
}

\begin{abstract}
Which is the more profitable way to sell a company: a public auction or an optimally structured negotiation with a smaller number of bidders? We show that under standard assumptions the public auction is always preferable, even if it forfeits all the seller's negotiating power, including the ability to withdraw the object from sale, provided that it attracts at least one extra bidder. An immodiate public auction also dominates negotiating while maintaining the right to hold an auction subsequently with more bidders. The results hold for both the standard independent private values model and a common values model. They suggest that the value of negotiating skill is small relative to the value of additional competition.
\end{abstract}

Jeremy Bulow

Graduate School of Business

Stanford University

Stanford, CA 94305

and NBER
Paul Klemperer

St. Catherine's College

Oxford

UNITED KINGDOM 


\section{Auctions vs. Negotiations}

\section{Introduction}

Consider a board of directors attempting to do its fiduciary duty of maximizing shareholder wealth. In incumbent management's hands the company is worth its current, publicly observed, stock price. A raider, or several raiders, privately approach the board, offering to buy the company at a premium to the current price. The raiders are willing to negotiate on price.

The board considers several options. The first option is to negotiate with the raiders for the best possible price. The second option is to publicly announce that the company is for sale, and hold an open auction among the raiders and any other bidders who may then emerge. A third option is to negotiate with the raiders, maintaining the right to hold an auction subsequently if the negotiations do not lead to a sale.

Which option is best? The advantage of negotiating is that the seller may be able to bargain the raiders into agreeing to pay a higher price by, for example, credibly threatening not to sell if the buyers' offers are too low, making an offer to one buyer that depends on information learned from other buyers, and maintaining the prerogative of discriminating among buyers' bids. We assume that the directors are extremely skilled at negotiations; in fact, we assume that they can use whatever sales mechanism will maximize expected profit from a given set of bidders.

The advantage of proceeding directly to an auction is that this is probably the strategy that will ensure maximum participation in the bidding. ${ }^{2}$ The problem is that publicizing a sale to increase the number of bidders may make it harder to

\footnotetext{
1 A public auction not only attracts extra bidders through the extra publicity, but also attracts extra bidders if bidding is costly, because for any given number of bidders the expected surplus per bidder is higher in an auction than if the seller negotiates optimally. (For analysis of optimal seller strategies with costly bidder participation, see Engelbrecht-Wiggans (1993), McAfee and McMillan (1987a), McAfee and Vincent (1991), and Shleifer and Vishny (1986).)
} 
negotiate effectively. In fact we will assume that putting the company "in play" by making it public knowledge that it is for sale makes it impossible for the company to be taken off the market, and forfeits all the seller's negotiating power, forcing the seller to simply accept the highest bid, provided it exceeds the current stock price. ${ }^{2}$

Finally, negotiating while maintaining the right to hold an auction if negotiations do not produce a sale reduces the cost of a failed negotiation, but makes negotiation less effective - buyers know that if none of them accedes to the seller's demands then they will have another chance to purchase the company.

The point of our paper is that the choice between these options is clear: Provided only that the auction will attract at least one extra bidder it yields the highest expected revenue, under standard assumptions. A direct auction with $N+1$ bidders beats an optimal negotiation with $N$ bidders, and is also superior to negotiating with $N$ bidders and then holding an auction with those $N$ bidders plus an additional bidder if negotiations fail.

We can prove these results even though we assume that a negotiator can use the techniques of mechanism design to precommit to any sales mechanism that maximizes the expected revenue from $N$ bidders, an assumption which undoubtedly overstates the bargaining ability of any real life negotiator. Furthermore, our assumption that an auctioneer must accept the highest offer among $N+1$ bidders, no matter how low, probably understates the power of a seller who holds an auction. Therefore, our result that an auction with $N+1$ bidders is better in expectation than any negotiation with $N$ bidders is conservative in some important respects.

2 One reason why a company might be forced to take the top bid once it announces an auction is that U.S. takeover law has the concept of a "moment of inevitability" at which a sale is thought to become inevitable, and "At this point, the duty of the board is said to change and become in effect that of a fair auctioneer who must seek the highest bid and may not consider long-run value maximization..." (Choper et. al.(1989), p.1152). A second reason is that the business of a company whose future ownership is thought to be uncertain may be damaged until the question of ownership is resolved and it may be hard to credibly withdraw the company from the market. See, e.g., Shleifer and Vishny (1988). 
In short, sellers, whether they are boards of directors of publicly held companies, or governments privatizing public sector companies, should focus on maximizing the number of potential bidders for their assets and should generally refuse to bargain with bidders who wish to pre-empt the auction process. ${ }^{3}$

Section 2 presents our model, which encompasses both private values and common values. Section 3 shows how to compute the expected revenue from any arbitrary sales mechanism that a seller might choose.

In section 4 we describe the optimal negotiating strategy. In general, it is to hold an English auction among the $N$ buyers until the top bidder is revealed. At this point, the seller should make a take-it-or-leave-it offer to the last remaining buyer, with the exact amount of the offer determined by the information that the seller learns through the auction bidding. (Often the take-it-or-leave-it offer will simply be the price at which the next-to-last bidder exits the auction.) We then compare the expected revenue from negotiating to that from a simple auction.

Section 5 gives some examples of our results.

In section 6 we show that moving directly to an auction is preferable to negotiating with the existing bidders before moving to an auction. Thus the seller should never accept any "lock-up" agreement that a buyer is willing to offer in return for not holding an auction with more buyers.

Section 7 extends our results to multiple unit auctions, and demonstrates an analogous result about the value of attracting new customers relative to the value of being able to charge a monopoly price.

The remaining sections show the effects of relaxing the assumptions in our basic model, and conclude.

3 By assuming a single seller, interested only in expected revenue we are abstracting from issues such as shareholders' individual incentives to sell (see, e.g., Grossman and Hart (1980), Hirshleifer and Titman (1990), and Holmstrom and Nalebuff (1992)), or management's interest in retaining control (see e.g. Harris and Raviv (1988)). 


\section{The Model}

A seller has been approached by $N \geq 1$ potential buyers. If she chooses to negotiate with them, she may impose any mechanism she wishes including, for example, discriminating between buyers, enforcing no-resale provisions, and credibly committing to consider only offers above some minimum amount. Alternatively she may choose to hold an auction. The auction will attract an additional $N+1$-st bidder, but once the auction is announced, the seller is then restricted to running a conventional ascending bid auction and to selling the object to the last remaining bidder at the price at which the next to last bidder drops out.

We normalize the seller's value of the object to zero. Each bidder $i$ observes a private signal $t_{i}$. We write $T$ for the vector $\left(t_{1}, \ldots, t_{N+1}\right)$. Conditional on the signals of all the potential buyers $i=1, \ldots, N+1$, the asset would be worth $v_{i}(T)$ to bidder $i$. We assume that $v_{i}(T)$ is differentiable everywhere, and $\frac{\partial v_{i}(T)}{\partial t_{i}}>0$ and $\frac{\partial v_{i}(T)}{\partial t_{j}} \geq 0 \forall i, j$.

Without loss of generality we can normalize so that all the $t_{i}$ are uniformly distributed on $[0,1]$. That is, a signal of $t_{i}=.23$ is more optimistic than 23 percent of the signals bidder $i$ might receive and less optimistic than 77 percent. In the special case of private values $v_{i}(T)$ is a function only of $t_{i}$, and in the special case of pure common values $v_{i}(T)=v_{j}(T)$.

We write $T^{N}$ for $\left(t_{1}, \ldots t_{N}\right)$. Contingent on the first $N$ signals we let the expected value of the asset to bidder $i$ be $v_{i}^{N}\left(T^{N}\right) \equiv E_{t_{N+1}}\left\{v_{i}(T)\right\}$. (More generally, we write $\mathrm{E}_{x}\{f(x, y)\}$ for the expectation of $f(x, y)$ contingent on $y$ and with respect to $x$.)

Let $p_{i}(T)$ be the probability that buyer $i$ will receive the object (in equilibrium), contingent on the vector of signals $T$, and let $p_{i}^{N}\left(T^{N}\right)$ be the probability that $i$ will receive the object (in equilibrium), contingent on $T^{N}$. Let $S_{i}\left(t_{i}\right)$ equal the expected surplus to buyer $i$. We let $d T_{-i}^{N} \equiv d t_{1}, \ldots, d t_{i-1}, d t_{i+1}, \ldots, d t_{N}$, and let $\int_{N}$ and $\int_{N+1}$ represent $N$ and $N+1$ integrals from 0 to 1 , respectively. 
We also make the following assumptions:

A.1 All bidders are risk neutral.

A.2 While $t_{i}$ is private information to bidder $i$, the value functions $v_{i}(\cdot)$ are common knowledge.

A.3 $v_{i}(1,1,1, \ldots 1)=\bar{v}<\infty$.

A.4 $v_{i}(0, \ldots 0) \geq 0$. Every bidder is a "serious bidder" willing to make an opening offer of zero, the seller's value, in an open English auction.

A.5 The variables $t_{1}, t_{2} \ldots t_{N+1}$ are independent.

A.6 Symmetry: Bidders' value functions are symmetric so $v_{i}\left(t_{1}, \ldots, t_{i}, \ldots, t_{j}, \ldots\right)=$ $v_{j}\left(t_{1}, \ldots, t_{j}, \ldots, t_{i}, \ldots\right)$, and bidders choose symmetric strategies in a conventional ascending bid auction.

A.7 $t_{i}>t_{j} \Rightarrow v_{i}(T),>v_{j}(T)$. (The bidders with the highest signals have the highest values.)

A.8 We define $\operatorname{MR}_{i}(T) \equiv \frac{-\partial}{\partial t_{i}}\left[\left(1-t_{i}\right) v_{i}(T)\right]=v_{i}(T)-\left(1-t_{i}\right) \frac{\partial v_{i}(T)}{\partial t_{i}}$, and analogously $\operatorname{MR}_{i}^{N}\left(T^{N}\right) \equiv v_{i}^{N}\left(T^{N}\right)-\left(1-t_{i}\right) \frac{\partial v_{i}^{N}\left(T^{N}\right)}{\partial t_{i}}=\mathrm{E}_{t_{N+1}}\left\{\mathrm{MR}_{i}(T)\right\}$. We assume that $t_{i}>t_{j} \Rightarrow \operatorname{MR}_{i}(T)>M_{j}(T)$.

Assumption A.8 is a standard regularity condition in auction theory. Note that $\left(1-t_{i}\right) v_{i}(T)$ is the expected revenue the seller would receive from $i$, if all the signals except $t_{i}$ were publicly known and the seller offered $i$ a take-it-or-leave-it price of $v_{i}(T)$. (This price would be accepted with probability $\left(1-t_{i}\right)$.) Thus MR is the marginal revenue from $i$, that is the increase in this expected revenue if the asking price were reduced, per extra unit sold, and our assumption corresponds to the standard assumption that marginal revenue is downward sloping.

We relax A.5 through A. 8 in sections 8,9 , and 10 .

4 Thus the bidder with the highest signal always wins such an auction. With pure common values (but not, it is believed, for any other cases of our model - see Bikhchandani and Riley (1993)), it is possible to construct asymmetric equilibria in which the bidder with the highest signal does not always win such an auction. 


\section{Profitability of Alternative Sales Procedures}

We begin by calculating the profitability of any arbitrary sales mechanism to $N$ bidders, $i=1, \cdots N$.

Begin by noting that in any sales procedure, the $i^{\text {ih }}$ bidder, with signal $t_{i}$ cannot, if he is behaving optimally, gain by deviating to the strategy he would use if he had signal $t_{i}{ }^{\prime}$, so

$$
\begin{aligned}
S_{i}\left(t_{i}\right) & \geq S_{i}\left(t_{i}{ }^{\prime}\right) \\
& +\int_{N-1}\left[v_{i}^{N}\left(T^{N}\right)-v_{i}^{N}\left(t_{1}, \ldots, t_{i-1}, t_{i}{ }^{\prime}, \ldots, t_{N}\right)\right] p_{i}^{N}\left(t_{1}, \ldots, t_{i-1}, t_{i}{ }^{\prime}, \ldots, t_{N}\right) d T_{-i}^{N} \\
& \forall t_{i}, t_{i}{ }^{\prime} .
\end{aligned}
$$

So $S_{i}\left(t_{i}\right)$ has derivative

$$
\frac{d S_{i}\left(t_{i}\right)}{d t_{i}}=\int_{N-1} \frac{\partial v_{i}^{N}\left(T^{N}\right)}{\partial t_{i}} p_{i}^{N}\left(T^{N}\right) d T_{-i}^{N}
$$

and therefore

$$
S_{i}(x)=S_{i}(0)+\int_{t_{i}=0}^{x} \int_{N-1} \frac{\partial v_{i}^{N}\left(T^{N}\right)}{\partial t_{i}} p_{i}^{N}\left(T^{N}\right) d T^{N}
$$

Therefore the expected surplus of the $N$ bidders equals

$$
\sum_{i=1}^{N} \int_{2=0}^{1}\left[S_{i}(0)+\int_{t_{i}=0}^{2} \int_{N-1} \frac{\partial v_{i}^{N}\left(T^{N}\right)}{\partial t_{i}} p_{i}^{N}\left(T^{N}\right) d T^{N}\right] d x
$$

equals (integrating by parts)

$$
\sum_{i=1}^{N}\left(S_{i}(0)+\int_{N}\left(1-t_{i}\right) \frac{\partial v_{i}^{N}\left(T^{N}\right)}{\partial t_{i}} p_{i}^{N}\left(T^{N}\right) d T^{N}\right) .
$$

Now expected seller profits can be written as the expected value of the good to the winning bidder, $\sum_{i=1}^{N} \int_{N} v_{i}^{N}\left(T^{N}\right) p_{i}^{N}\left(T^{N}\right) d T^{N}$, less the expected surplus of the $N$ bidders. It follows that

Lemma 0: The expected profits from a sales procedure involving $N$ bidders equal $\sum_{i=1}^{N}\left(\int_{N} \mathrm{MR}_{i}^{N}\left(T^{N}\right) p_{i}^{N}\left(T^{N}\right) d T^{N}-S_{i}(0)\right)$. 
This interpretation of the seller's profits in terms of the marginal revenues of the bidders weighted by their probabilities of receiving the object follows Bulow and Roberts (1989) but extends their private-values model to the general commonvalues case. The result is also a straightforward extension of Myerson's (1981) model which is restricted to a specific form of common values in which players' values are additive functions of signals.

\section{Auctions vs. Negotiations}

\section{Optimal Negotiations}

Lemma 0 implies that no sales procedure can earn greater profits than a procedure in which $S_{i}(0)=0 \forall i$ (obviously no sales procedure can give any type of bidder a negative expected surplus), the good is always given to the bidder $i$ for whom $\operatorname{MR}_{i}^{N}\left(T^{N}\right)$ is largest if that value is greater than zero (that is, $p_{i}^{N}\left(T^{N}\right)=1$ for this bidder and $p_{j}^{N}\left(T^{N}\right)=0$ for all other bidders, $\left.j \neq i\right)$, and the good is not sold if the largest $\operatorname{MR}_{i}^{N}\left(T^{N}\right)$ is negative (that is, $p_{i}^{N}\left(T^{N}\right)=0 \forall i$ in this case). ${ }^{s}$

But all this can be achieved under our assumptions by using the following modification of a standard open English auction. Let the price rise continuously and, at the point at which the next to last bidder drops out, offer the last bidder a take-it-or-leave-it price equal to the maximum of the current price and the price this bidder, $i$, would just be willing to pay if his $\operatorname{MR}_{i}^{N}\left(T^{N}\right)$ were zero (given the information that can now be inferred about other bidders' signals). To see this yields the desired outcome, observe that if the seller uses this procedure each bidder will drop out of the bidding at the price he would just be willing to pay if all the remaining active bidders had signals equal to his own, ${ }^{6}$ so (i) a bidder of the lowest

5 Under our assumptions, the probability of two bidders having identical MRs is zero, and any allocation suffices in this case.

6 To see this, note that, given all other bidders follow this rule (and inferring the signals of bidders who have dropped out using this assumption), a bidder is happy (unhappy) to find himself the winner at any price below (above) this stopping price. Strictly, bidders with very low signals are indifferent about participating since they know that they would never meet the seller's take-it-or-leave-it price. However, the 
possible type, $t_{i}=0$, wins with probability zero, so $S_{i}(0)=0$, (ii) the bidder, $i$, who has the highest signal $t_{i}$, will be the final bidder, so the winner (if any) will also be the bidder with the highest $\mathrm{MR}_{i}^{N}\left(T^{N}\right)$, and (iii) the signal $t_{j}$ of every bidder $j$ who drops out can be inferred by the price at which that bidder leaves the auction, so the final take-it-or-leave-it price can be set using precise information about all the other bidders' signals to ensure that the high bidder $i$ wins if and only if $\operatorname{MR}_{i}^{N}\left(T^{N}\right) \geq 0$. It follows therefore that

Lemma 1: The expected profits from an optimal negotiation with $N$ bidders equal $E_{T^{N}}\left\{\max \left\{\operatorname{MR}_{1}^{N}\left(T^{N}\right), \operatorname{MR}_{2}^{N}\left(T^{N}\right), \ldots, \operatorname{MR}_{N}^{N}\left(T^{N}\right), 0\right\}\right\}$.

We note that unless bidder valuations are "private," so that $v_{i}(\cdot)$ depends only on $t_{i}$, information about other valuations is useful in setting the final take-it-orleave-it price, so that alternative mechanisms which do not reveal the signals of the losing bidders will not in general be revenue equivalent to the mechanism described.

\section{A uctions}

Following the derivation of Lemma 0 , the expected profits from a sales procedure to $N+1$ bidders are

$$
\sum_{i=1}^{N+1}\left(\int_{N+1} \operatorname{MR}_{i}(T) p_{i}(T) d T-S_{i}(0)\right)
$$

But in any standard auction with symmetric bidders, ${ }^{7}$ the bidder with the highest actual signal wins the auction, so $p_{i}(T)=1$ if $t_{i}$ is the highest actual signal and $p_{i}(T)=0$ otherwise, and a bidder of the lowest possible type wins with probability zero, so $S_{i}(0)=0$. Therefore

seller can induce all bidders to participate at an arbitrarily small cost in expected revenue by committing to foregoing the take-it-or-leave-it offer with a probability approaching zero and to always accepting the highest bid in this event.

7 Including, for example, a Dutch auction, or a first-price sealed bid or a secondprice sealed bid auction, as well as the open ascending (English) auction on which
we are focusing. 
Lemma 2: The expected profits from an auction with $N+1$ bidders equal $\mathrm{E}_{T}\left\{\max \left\{\mathrm{MR}_{1}(T), \mathrm{MR}_{2}(T), \ldots, \mathrm{MR}_{N+1}(T)\right\}\right\}$.

Lemmas 1 and 2 allow us to prove our main theorem:

Theorem: The expected profits from an auction with $N+1$ bidders exceed the expected profits from a negotiation with $N$ bidders.

Proof: For each realization of $T^{N}$, either, for some $i$,

$$
\max \left\{\operatorname{MR}_{1}^{N}\left(T^{N}\right), \ldots \mathrm{MR}_{N}^{N}\left(T^{N}\right), 0\right\}=\operatorname{MR}_{i}^{N}\left(T^{N}\right)=\mathrm{E}_{t_{N+1}}\left\{\mathrm{MR}_{i}(T)\right\}
$$

or

$$
\begin{aligned}
& \max \left\{\operatorname{MR}_{1}^{N}\left(T^{N}\right), \ldots \mathrm{MR}_{N}^{N}\left(T^{N}\right), 0\right\}=0 \\
& \leq v_{N+1}\left(T^{N}, 0\right)=\int_{0}^{1}-\frac{\partial}{\partial t_{N+1}}\left[\left(1-t_{N+1}\right) v_{N+1}\left(T^{N}, t_{N+1}\right)\right] d t_{N+1} \\
&=\int_{0}^{1} \operatorname{MR}_{N+1}(T) d t_{N+1}=\mathrm{E}_{t_{N+1}}\left\{\operatorname{MR}_{N+1}(T)\right\}
\end{aligned}
$$

So, in either case, for all $T^{N}$,

$$
\begin{aligned}
\max \left\{\mathrm{MR}_{1}^{N}\left(T^{N}\right), \ldots \mathrm{MR}_{N}^{N}\left(T^{N}\right), 0\right\} & \leq \max \left\{\mathrm{E}_{t_{N+1}}\left\{\mathrm{MR}_{1}(T)\right\}, \ldots \mathrm{E}_{t_{N+1}}\left\{\mathrm{MR}_{N+1}(T)\right\}\right\} \\
& \leq \mathrm{E}_{t_{N+1}}\left\{\max \left\{\mathrm{MR}_{1}(T), \ldots \mathrm{MR}_{N+1}(T)\right\}\right\}
\end{aligned}
$$

and since the inequalities are strict for a set of $T^{N}$ that occur with positive probability, we have

$$
\mathrm{E}_{T^{N}}\left\{\max \left\{\mathrm{MR}_{1}^{N}\left(T^{N}\right), \ldots \mathrm{MR}_{N}^{N}\left(T^{N}\right), 0\right\}\right\}<\mathrm{E}_{T}\left\{\max \left\{\mathrm{MR}_{1}(T), \ldots \mathrm{MR}_{N+1}(T)\right\}\right\}
$$

Q.E.D.

The argument of the proof is straightforward: The expected marginal revenue of a bidder computed over all his possible values equals his lowest possible value (just as the average marginal revenue of any demand curve computed up to some quantity equals the average revenue, that is, the price, at that quantity), and the 
lowest possible value of any serious bidder exceeds zero by assumption. Thus in expectation the MR of the $(N+1)$ st bidder is at least as good as the zero that negotiation provides. But the added variance of the $M R$ of the $(N+1)$ st bidder is also helpful, given that the option of choosing one of the MRs of the first $N$ bidders is available. So the auction is clearly better.

Note, however, that there is no simple dominance relationship between an auction with $N+1$ bidders and a negotiation with $N$ bidders. For example, an auction with two bidders with private values drawn uniformly from $[0,1]$ performs worse than a negotiation with 1 bidder, averaged across states in which the first

bidder's value actually exceeds $\frac{1}{2}$ (that is, MR exceeds 0 ), but performs better than the negotiation averaged across the remaining states. Thus it is only by expressing expected profits in the forms given in Lemmas 1 and 2 that our result becomes apparent.

\section{Examples}

If the seller negotiates with one bidder, with a value drawn from a uniform distribution on $[0,1]$, then it is easy to check her optimal strategy is to offer a take-it-or-leave-it price of $\frac{1}{2}$. The seller's expected profit is $\frac{1}{4}$. Alternatively, an auction with two bidders, each with private valuations drawn independently from this distribution would yield expected profit equal to the expected second highest valuation, or $\frac{1}{3}$.

More generally, the expected profit from an open auction with $N+1>1$ bidders whose values are drawn independently from a uniform distribution on $[0, \bar{v}]$ is $\frac{N}{N+2} \bar{v}$. Since $v_{i}=t_{i} \bar{v}, M_{i}=\bar{v}\left(2 t_{i}-1\right)$, so $\mathrm{MR}_{i}=0$ at $t_{i}=1 / 2$. Therefore, the optimal negotiation strategy is to run an auction with a minimum price of $\frac{b}{2}$. Thus, the expected profit from negotiating with $N$ bidders will be $\frac{N-1+2^{-N}}{N+1} \bar{v}$, less than the profit from the absolute auction with $N+1$ bidders.

As a second example, consider a common value auction in which the true value of an item is the same to each bidder, namely the product of $t_{1}, t_{2}$, and $t_{3}$, where 
all the signals are drawn independently from a uniform distribution on $[0,1]$. Each potential bidder observes one of the signals. Then a seller negotiating with two bidders would optimally begin with a continuous English auction. Each bidder, will compute his strategy by averaging over all the possible values of the third signal, which in this case is equivalent to assuming that this signal takes on its expected value of $\frac{1}{2}$. So each bidder $i$ would drop out in equilibrium at a price of $\frac{1}{2}\left(t_{i}\right)^{2} \equiv D$, which would be his value if his competitor also observed the same signal. After one bidder has dropped out, the remaining bidder $j$ has a value uniformly distributed between $D$ and $\frac{1}{2}\left(t_{i}\right)$. This implies that $v_{j}=\frac{1}{2}\left(t_{i}\right)\left(t_{j}\right)$ and $\mathrm{MR}_{j}=\frac{1}{2}\left(t_{i}\right)\left(2 t_{j}-1\right)$, so $\mathrm{MR}_{j}=0 \Rightarrow t_{j}=\frac{1}{2} \Rightarrow v_{j}=\frac{1}{4} t_{i}=\sqrt{D / 8}$. So the seller should set a take-it-orleave-it price of $\sqrt{D / 8}$ if this exceeds $D$, that is, if $D<1 / 8$, but if $D>\frac{1}{8}$ then the seller should simply agree to sell to $j$ at the dropout price $D$. The addition of the take-it-or-leave-it price adds 6.25 percent to the revenue expected when there are two bidders but no take-it-or-leave-it offer. But having a third bidder and no ability to make a take-it-or-leave-it offer would add 20 percent. $^{8}$

\section{Negotiations followed by an Auction}

The seller cannot benefit by first negotiating with $N$ bidders while reserving the right to hold an auction among all $N+1$ bidders if the negotiations fail-this can do no better than proceeding directly to an auction. (That is, it would be optimal to set a take-it-or-leave-it price in the negotiation phase that is so high that it is never accepted.)

The reason is that if the seller has the option of resorting to the auction, it will be obvious to all that if negotiations fail, there will be an auction. Viewing the two-stage process as a whole, then, the seller is constrained to choosing among mechanisms that always lead to a sale. But clearly any optimal mechanism that

\footnotetext{
8 The values are: $\frac{1}{12}=\frac{16}{192}$ for two bidders and no final take-it-or-leave-it offer; $\frac{17}{192}$ for two bidders and a final take-it-or-leave-it offer, and $\frac{1}{10}$ for three bidders and
no final take-it-or-leave-it offer.
} 
always sells must always sell to the buyer with the highest signal. Therefore, it will not be optimal to sell in the negotiation stage unless it is certain that the buyer's signal is greater than or equal to the signal of the $N+1$ st bidder. Therefore the seller should insist on a price in the negotiation phase that will only be accepted when a buyer gets a signal of 1 , which occurs with probability zero.

Therefore, under our assumptions, the seller should not accept any high "lockup" bid that a buyer may be willing to offer in return for not holding an auction with an additional buyer. ${ }^{2}$

\section{Multiple Units}

If a seller is offering $X$ identical goods for sale, then negotiating optimally with $N$ bidders each interested in buying one unit will yield lower expected revenue than holding an auction that awards units to the top $X$ among $N+X$ bidders.

It is easy to generalize our analysis to show that the expected profits from the auction equals the expected sum of the $X$ highest values among $\mathrm{MR}_{1}(T), \mathrm{MR}_{2}(T), \ldots$, $\mathrm{MR}_{N+X}(T)$, while expected profits from the negotiation are the expected sum of the $X$ highest values among $\mathrm{MR}_{1}^{N}\left(T^{N}\right), \mathrm{MR}_{2}^{N}\left(T^{N}\right), \ldots, \mathrm{MR}_{N}^{N}\left(T^{N}\right)$ and $X$ zeros. ${ }^{1011}$ It follows as before that the auction yields greater expected profits.

9 This result would be unaffected by other bidders having costs of entering the auction. (But the presence of such costs can explain why bidders may jump bid to deter competitors from entering; see Fishman (1988) and Png (1985). See also Avery (1993), Daniel and Hirshleifer (1993), and von der Fehr (1993) for related discussion.)

${ }^{10}$ For this section only, we define $T \equiv\left(t_{1}, \ldots, t_{N+X}\right)$ and we define $\mathrm{MR}_{i}^{N}\left(T^{N}\right) \equiv$ $\mathrm{E}_{t_{N+1}, \ldots, t_{N+x}}\left\{\mathrm{MR}_{i}(T)\right\}$.

11 See our forthcoming paper, Bulow and Klemperer (1994), for a further analysis of multiple unit auctions. Optimal negotiation is in general more complex than in the single unit case since determining any bidder's MR requires knowing all other bidders' signals. One way to achieve optimal negotiation is (i) ask each bidder $i$ to independently report his signal $t_{i}$ (in equilibrium all reports will be honest), and let $\hat{t}$ be the $(X+1)$ st highest signal reported; (ii) for each $i$ who reports a signal in the top $X$ signals, compute $\tilde{t}_{i}$ s.t. $\operatorname{MR}_{i}^{N}\left(t_{1}, \ldots t_{i-1}, \tilde{t}_{i}, t_{i+1}, \ldots t_{N}\right)=0$ and sell to this bidder if $t_{i} \geq \tilde{t}_{i}$, at the maximum of $v_{i}\left(t_{1}, \ldots t_{i-1}, \tilde{t}, t_{i+1}, \ldots t_{N}\right)$ and $v_{i}\left(t_{1}, \ldots t_{i-1}, \hat{t}, t_{i+1}, \ldots t_{N}\right)$. 
An interesting application of this result is to a competitive industry with constant marginal costs $c$ up to a fixed capacity $X$, and demand $N$ at a price of $c$. Provided the (industry) marginal revenue curve is downward sloping, the industry would earn more revenue from a marketing program that multiplied demand horizontally by the factor $(N+X) / N$, than it would earn from perfect collusion at the monopoly price.

\section{Non-independent Signals}

\section{Negotiating with One vs. Auctioning with Two}

Affiliated signals reinforce our conclusion that an auction with two bidders is more profitable than negotiating with a single bidder: Let $G\left(x_{1}, x_{2}\right)$ be the probability that $t_{1} \geq x_{1}$ and $t_{2} \geq x_{2}$. Then, with affiliated signals, the probability that $t_{2} \geq x$, conditional on $t_{1} \geq x$, is greater than or equal to the unconditional probability, $1-x$, that $t_{2} \geq x$, so we have

$$
G(x, x) \geq(1-x)^{2}
$$

In a standard ascending auction the expected revenue is just the minimum of $v_{1}\left(t_{1}, t_{1}\right)$ and $v_{2}\left(t_{2}, t_{2}\right)$. (Since bidder $i$ would be pleased to win at any lower price than $v_{i}\left(t_{i}, t_{i}\right)$ but would not wish to find himself the winner at any higher price.) Therefore, the probability that the seller will earn at least $v_{1}(x, x)$ dollars is $G(x, x)$, and expected revenue can be written as

$$
v_{1}(0,0)+\int_{0}^{1} \frac{d v_{1}(x, x)}{d x} G(x, x) d x \geq v_{1}(0,0)+\int_{0}^{1} \frac{d v_{1}(x, x)}{d x}(1-x)^{2} d x
$$

The right hand side of the above is the expected revenue when there is the same unconditional distribution but independent draws. Therefore, since two independent bidders yield more revenue than optimally negotiating with one bidder, two affiliated bidders in an auction must yield more revenue than one bidder in a 
negotiation. ${ }^{12}$

\section{Negotiating With Multiple Bidders}

When more than one bidder is available for a negotiation, and their signals are not independent, a shrewd negotiator may be able to do better than an English auction with continuously rising prices and a final take-it-or-leave-it offer.

As an example, consider a seller negotiating with two buyers. Each bidder knows his own value precisely, $v_{1}=A+B$ and $v_{2}=C+B$, where $A, B$, and $C$ are all distributed independently and uniformly on $[0,1]$, but bidders do not know the values of $A, B$, or $C$ individually, so the observed variables $v_{1}$ and $v_{2}$ are affiliated. ${ }^{13}$ Now consider the all-pay mechanism where each bidder submits a non-refundable non-negative bid for the object, with the object going to the highest bidder. (That is, if you bid 40 cents, then your payment is 40 cents, regardless of whether you win the object or not.)

It is easy to show that the symmetric equilibrium bids are $b\left(v_{i}\right)=\frac{1}{2} v_{i}^{2}$. Remarkably, each bidder's expected surplus is zero regardless of his value, so the expected revenue to the seller is the expected value of the higher of the two bidders, which is $7 / 6$. By comparison, adding a third symmetric bidder (with valuation $B+D$ with $D$ also independently and uniformly distributed on $[0,1])$ would make expected revenue equal to the expected second highest value of the three bidders, that is, 1 , in an auction.

More generally, if a negotiator has the power to design mechanisms that extract

12 Affiliation implies correlation, but not vice-versa. With negative correlation between the bidders' signals, negotiating with one may be more profitable than auctioning with two. An example has $t_{1}+t_{2}=1$ and any $v_{i}(T)$ satisfying $v_{1}(T)<t_{1}$ if $0<t_{1}<1 / 2 ; v_{1}(T)>1 / 2$ if $t_{1}>1 / 2$.

13 In terms of $t_{1}$ and $t_{2}$, this example translates to:

$$
\begin{aligned}
& v_{i}(T)=\left(2 t_{i}\right)^{1 / 2} \quad 0 \leq t_{i} \leq 1 / 2 \quad i=1,2 \\
& v_{i}(T)=2-\left(2\left(1-t_{i}\right)\right)^{1 / 2} \quad 1 / 2 \leq t_{i} \leq 1 \quad i=1,2
\end{aligned}
$$


all surplus, as in, for example, Cremer \& McLean (1985), then an extra bidder can never make up for the loss of this power. ${ }^{14}$ However, in an example such as the one above, a seller will do better with $N+1$ bidders in an auction than with $N$ bidders in an auction followed by an optimal negotiation with (that is, a take-it-or-leave-it offer to) the last of the $N$ bidders.

In particular, assume that each bidder $i$ 's signal derives from an independent component $x_{i}$ transformed by some common random function $g(\cdot)$, so each bidder observes $g\left(x_{i}\right)$ and has value $v_{i}\left(g\left(x_{1}\right), \ldots, g\left(x_{N+1}\right)\right) \forall i$, such that it remains true that the highest value bidder has the highest MR. (In our example above, $g\left(x_{i}\right)=$ $x_{i}+B$, in which $x_{1}=A$ and $x_{2}=C$.) Then if the seller had perfect information about $g(\cdot)$, her problem of setting the optimal reservation price at the end of the game with $N$ bidders would be just the same as in the independent signals case. However, we know that even with an optimal take-it-or-leave-it offer contingent on knowing $g(\cdot)$, the seller does worse in expectation than with the $N+1$ bidders in an auction. (Bidders are unaffected by whether or not they know $g(\cdot)$, with or without a final take-it-or-leave-it offer, since their optimal strategies depend only on the actual signals, which are inferred exactly as when they are independent.) It

14 For any given $T^{N}$, relabel the first $N$ bidders so that $t_{1} \geq \ldots \geq t_{N}$. Then for this $T^{N}$ an open auction with $(N+1)$ bidders yields

$$
\begin{aligned}
& E_{t_{N+1}}\left\{v_{1}\left(t_{1}, t_{2}, \ldots, t_{N}, t_{1}\right) \mid t_{N+1} \geq t_{1}\right\} \operatorname{Prob}\left(t_{N+1} \geq t_{1}\right) \\
& \quad+E_{t_{N+1}}\left\{v_{N+1}\left(t_{N+1}, t_{2}, \ldots t_{N}, t_{N+1}\right) \mid t_{1}>t_{N+1} \geq t_{2}\right\} \operatorname{Prob}\left(t_{1}>t_{N+1} \geq t_{2}\right) \\
& \quad+E_{t_{N+1}}\left\{v_{2}\left(t_{2}, t_{2}, \ldots t_{N}, t_{N+1}\right) \mid t_{2}>t_{N+1}\right\} \operatorname{Prob}\left(t_{2}>t_{N+1}\right)
\end{aligned}
$$

which is less than the value of extracting all the surplus from the highest of the $N$ bidders which is

$$
\begin{aligned}
& E_{t_{N+1}} v_{1}\left(t_{1}, t_{2}, \ldots t_{N}, t_{N+1}\right) \\
& =E_{t_{N+1}}\left\{v_{1}\left(t_{1}, t_{2}, \ldots t_{N}, t_{N+1}\right) \mid t_{N+1} \geq t_{1}\right\} \operatorname{Prob}\left(t_{N+1} \geq t_{1}\right) \\
& \quad+E_{t_{N+1}}\left\{v_{1}\left(t_{1}, t_{2}, \ldots t_{N}, t_{N+1}\right) \mid t_{1}>t_{N+1} \geq t_{2}\right\} \operatorname{Prob}\left(t_{1}>t_{N+1} \geq t_{2}\right) \\
& \quad+E_{t_{N+1}}\left\{v_{1}\left(t_{1}, t_{2}, \ldots t_{N}, t_{N+1}\right) \mid t_{2}>t_{N+1}\right\} \operatorname{Prob}\left(t_{2}>t_{N+1}\right) .
\end{aligned}
$$


follows that, absent information about $g(\cdot)$, the seller prefers auctioning with $N+1$ to negotiating with $N$.

\section{Asymmetric Bidders}

Witb asymmetric bidders, the optimal negotiation would always entail sale to the bidder with the highest positive MR, which may be different from the person with the highest value. That is, tbe seller will choose a mechanism that discriminates among buyers in the same way that a monopolist will price discriminate across markets, equating MR rather than price. In this case, optimal negotiation may succeed in achieving a higher expected MR and, tberefore, a higher expected revenue than an auction with an extra bidder.

For example, assume in a private values setting that $v_{1}(T)=100 t_{1}$ and $v_{2}(T)=$ 50. Then, witb either $v_{3}(T)=100 t_{3}$ or $v_{3}(T)=50$, an auction witb all three bidders will yield expected revenue of $50 .{ }^{13}$ Now consider an optimal negotiation with bidders 1 and 2 . The seller would give 1 a take-it-or-leave-it price of 75 , promising to sell to 2 for 50 if 1 turns ber down. Expected revenue becomes $.25(75)+.75(50)=$ $56.25 .^{16}$

\section{0. "Irregular" Distributions}

Our assumption of symmetric bidders, (A.6), does not by itself guarantee that

13 If $v_{3}(T)=50$, then the value of the second bighest bidder will always be 50 , and that will be the revenue from an auction. If $v_{3}(T)=100 t_{3}$, one time in four both $v_{1}(T)$ and $v_{3}(T)$ will be less than 50 , and expected revenue will be the higher of their two values, on average $33 \frac{1}{3}$. Similarly, once in four times botb $v_{1}(T)$ and $v_{3}(T)$ will exceed 50 , and expected revenue will be tbe lower of the two values, on average $66 \frac{2}{3}$. Finally, fifty percent of the time $v_{2}(T)$ will be the second highest value, and revenue will be 50. So total expected revenue is $\frac{1}{4}\left(33 \frac{1}{3}\right)+\frac{1}{4}\left(66 \frac{2}{3}\right)+\frac{1}{2}(50)=50$.

16 The superior revenue would generally hold even if resale were permitted. The seller could immediately get a take-it-or-leave-it price from buyer 2 of 56.25 , and leave it to 2 to offer 1 a take-it-or-leave-it price of 75 , for example. (75 is the optimal take-it-or-leave-it price for buyer 2 to demand from buyer 1 since buyer 1 's MR is just equal to 50 , buyer 2's value, if buyer 1's value is 75 .) 
the bidder with the highest signal will have the highest MR. ${ }^{17}$ If assumption (A.8) fails, then the bidder with the highest signal may not have the highest $M R$, and an optimal negotiation might be preferable to an auction with an extra bidder.

For example, consider the following case:

$$
v_{i}(T)=\left\{\begin{array}{lll}
\frac{1}{3\left(1-t_{i}\right)}-\frac{1}{3} & \frac{1}{3} \geq t_{i} \geq 0 & \mathrm{MR}_{i}(T)=-\frac{1}{3} \\
\frac{6}{9\left(1-t_{i}\right)}-\frac{2}{3} & \frac{2}{3}>t_{i}>\frac{1}{3} & \mathrm{MR}_{i}(T)=-\frac{2}{3} \\
1 & 1 \geq t_{i} \geq \frac{2}{3} & \mathrm{MR}_{i}(T)=1
\end{array}\right.
$$

Optimal negotiation with $N$ bidders with signals drawn independently from this distribution involves setting a take-it-or-leave-it price of 1 (and any arbitrary allocation among bidders willing to pay this price when there is more than one such bidder ${ }^{18}$ ). Expected revenue is $1-\left(\frac{2}{3}\right)^{N}$. A simple auction with $N+1>1$ bidders would yield only $1-\left(\frac{2}{3}\right)^{N}-\frac{1}{9}\left(\left(\frac{2}{3}\right)^{N}-\left(\frac{1}{3}\right)^{N}\right) \cdot{ }^{19}$

\section{Conclusions}

When a company is approached by a potential buyer or buyers, its options may be either to negotiate or to put the company up for auction. Our analysis implies that if the board expects at least one extra serious bidder to appear in an auction, then it should generally not negotiate and should directly begin an auction.

Of course, institutional considerations may make any given situation more complex. For example, if allowing many bidders access to confidential financial infor-

17 The analog for monopoly is that, even though demand curves must be downward sloping, MR curves may not be.

18 Note that the distribution of values for a bidder is continuous in this example. Strictly, we violate (A.7) for $t_{i} \geq 2 / 3$, but by making $v_{i}(T)=1+\epsilon\left(t_{i}-\frac{2}{3}\right)$ for $t_{i}>2 / 3, \epsilon$ small, we would have an example that satisfied all assumptions except (A.8).

19 With probability $1-\left(\frac{2}{3}\right)^{N+1}$, the winning bidder has a signal exceeding $\frac{2}{3}$ and a MR of 1 ; with probability $\left(\frac{1}{3}\right)^{N+1}$, no bidder's signal exceeds $\frac{1}{3}$, so the winner's MR is $-\frac{1}{3}$; with the remaining probability, $\left(\frac{2}{3}\right)^{N+1}-\left(\frac{1}{3}\right)^{N+1}$, the winner's MR must therefore equal $-\frac{2}{3}$. So the expected MR of the winning bidder is $\left(1-\left(\frac{2}{3}\right)^{N+1}\right)+$ $\left(\frac{1}{3}\right)^{N+1}\left(-\frac{1}{3}\right)+\left(\left(\frac{2}{3}\right)^{N+1}-\left(\frac{1}{3}\right)^{N+1}\right)\left(-\frac{2}{3}\right)$. 
mation would cause the company's value to be diminished to the eventual buyer, then one might wish to restrict bidding.

But remember that our analysis assumed that a seller could negotiate optimally, making credible commitments of the sort that might not be possible in real life, and we also assumed that bidders had no bargaining power in a negotiation. We therefore believe that our basic result does not overstate the efficacy of auctions relative to negotiations. Certainly a firm that refused to negotiate with a potential buyer, and instead put itself up for auction, should be presumed to have exercised reasonable business judgment. 


\section{References}

Avery, Christopher. "Strategic Jump Bidding and English Auctions." Discussion paper. Kennedy School of Government, Harvard University (1993).

Bikhchandani, Sushil, and Riley, John G. "Equilibria in Open Auctions." Unpublished manuscript, University of California, Los Angeles (September 1993).

Bulow, Jeremy I. and Klemperer, Paul D. "Auctions vs. Negotiations." Stanford Business School Working Paper (1993).

Bulow, Jeremy I. and Klemperer, Paul D. "Rational Frenzies and Crashes." J. Pol. Econ. 102 (February 1994):forthcoming.

Bulow, Jeremy I., and Roberts, D. John. "The Simple Economics of Optimal Auctions." J. Pol. Econ. 97 (October 1989): 1060-90.

Choper, Jesse H., Coffee, John C. Jr., and Morris, C. Robert Jr. Cases and Materials on Corporations. Third Edition. Boston: Little, Brown (1989).

Cremer, Jacques, and McLean, Richard. "Optimal Selling Strategies under Uncertainty for a Discriminatory Monopolist when Demands Are Interdependent." Econometrica 53 (March 1985): 345-361.

Daniel, Kent and Hirshleifer, David. "A Theory of Costly Sequential Bidding." Graduate School of Business, University of Chicago, manuscript (1993).

Englebrecht-Wiggans, Richard. "Optimal Auctions Revisited." Games and Eco. nomic Behavior 5 (1993): 227-39.

von der Fehr, Nils Henrik. "Predatory Bidding in Sequential Auctions." Discussion paper. Department of Economics, University of Oslo (1993).

Fishman, Michael J. "A Theory of Pre-emptive Takeover Bidding." Rand J. Econ. 19 (Spring 1988): 88-101. 
Grossman, Sanford J. and Hart, Oliver D. "Takeover Bids, the Free-Rider problem, and the Theory of the Corporation." Bell Journal of Economics 11 (1980): 42-64.

Harris, Milton, and Raviv, Artur. "Corporate Control Contests and Capital Structure." Journal of Financial Economics 20(1/2) (1988): 55-86.

Hirshleifer, David and Titman, Sheridan. "Share Tendering Strategies and the Success of Hostile Takeover Bids." Journal of Political Economy 98(2) (1990): 295324.

Holmstrom, Bengt and Nalebuff, Barry. "To the Rajder Goes the Surplus? A Reexamination of the Free-Rider Problem." Journal of Economics and Management Strategy 1(1) (November 1992).

McAfee, R. Preston, and McMillan, John. "Auctions with Entry." Economics Letters 23 (1987a): 343-347.

McAfee, R. Preston, and McMillan, John. "Auctions and Bidding." Journal of Economic Literature 25 (June 1987b): 699-738.

McAfee, R. Preston and Vincent, Daniel. "Updating the Reserve Price in Common Value Auctions." Unpublished manuscript, University of Texas, Austin (December 1991).

Myerson, Roger B. "Optimal Auction Design." Math. Operations Res. 6 (February 1981): 58-73.

Png, Ivan P.L. "The Information Conveyed by a Takeover Bid." UCLA Anderson Graduate School of Management Working Paper No. 3-85, (February 1985).

Shleifer, Andrei, and Vishny, Robert W. "Greenmail, White Knights, and Shareholders' Interest." Rand. J. Econ. 17 (Autumn 1986): 293-309.

Shleifer, Andrei, and Vishny, Robert W. "Value Maximization and the Acquisition Process." J. Econ. Perspectives 2 (Winter 1988): 7-20. 